\title{
Efficacy of Skull Plain Films in Follow-up Evaluation of Cerebral Aneurysms Treated with Detachable Coils: Quantitative Assessment of Coil Mass
}

S.J. Ahn, B.M. Kim, W.S. Jung, and S.H. Suh

\begin{abstract}
BACKGROUND AND PURPOSE: Skull plain films of coiled aneurysms have been used in a limited role, including morphologic comparison of the coil mass. We aimed to evaluate the efficacy of skull plain films in patients treated with detachable coils by using quantitative assessment.
\end{abstract}

MATERIALS AND METHODS: In this retrospective study, 78 pairs of the initial and follow-up skull anteroposterior and lateral images were reviewed independently by 2 neuroradiologists. The largest diameter, the perpendicular diameter, and area of the coil mass were measured separately on plain film, and quantitative changes of parameters were compared between subgroups, which were determined by consensus, depending on the need for retreatment. Subgroup analysis was also performed according to aneurysm size, packing attenuation, and ruptured status.

RESULTS: On skull lateral images, mean quantitative changes of the largest diameter $(0.53 \pm 0.43 \mathrm{~mm}$ versus $1.17 \pm 0.91 \mathrm{~mm}, P<.01)$, the perpendicular diameter $(0.56 \pm 0.48 \mathrm{~mm}$ versus $1.20 \pm 1.05 \mathrm{~mm}, P<.01)$, and the area of the coil mass $\left(5.21 \pm 7.51 \mathrm{~mm}^{2}\right.$ versus $10.55 \pm 10.93$ $\left.\mathrm{mm}^{2}, P<.02\right)$ differed significantly between subgroups. Receiver operating characteristic analysis showed quantitative change of the largest diameter (>1.1 mm; sensitivity, 50.0\%; specificity, 90.3\%), the perpendicular diameter (>.9 mm; sensitivity, $62.5 \%$; specificity, $85.5 \%$ ), and the area (>8.5 $\mathrm{mm}^{2}$; sensitivity, $50.0 \%$; specificity, $83.9 \%$ ) on skull lateral films to be indicative of aneurysm recurrence, and the diagnostic accuracy of these parameters increased significantly in the high-packing-attenuation group.

CONCLUSIONS: Quantitative measurement of the coil mass by using skull plain lateral images has the potential to predict aneurysm recurrence in follow-up evaluations of intracranial aneurysms with coiling.

ABBREVIATIONS: $\mathrm{A}_{\mathrm{AP}}=$ area on the anteroposterior view; $\mathrm{A}_{\mathrm{Lat}}=$ area on the lateral view; $\mathrm{AP}=$ anteroposterior; $\mathrm{L}_{\mathrm{AP}}=$ largest diameter of coil mass on the anteroposterior view; $\mathrm{L}_{\mathrm{Lat}}=$ largest diameter on the lateral view; $\mathrm{P}_{\mathrm{AP}}=$ diameter perpendicular to the $\mathrm{L}_{\mathrm{AP}} ; \mathrm{P}_{\mathrm{Lat}}=$ diameter perpendicular to the $\mathrm{L}_{\mathrm{Lat}}$

E

ndovascular treatment with detachable coils has proved to be a safe and effective technique for patients with intracranial aneurysm. ${ }^{1,2}$ However, the major drawback is that $14 \% \sim 33 \%$ of coiled aneurysms may be recanalized due to coil compaction, which will need retreatment. ${ }^{3-5}$

Therefore, follow-up imaging is essential for patients with coiled aneurysms. While DSA is still a criterion standard, MRA is becoming an alternative in follow-up imaging of coiled aneu-

Received May 8, 2014; accepted after revision August 13.

From the Department of Radiology (S.J.A., W.S.J., S.H.S.), Gangnam Severance Hospital; Department of Radiology (B.M.K.); and Severance Institute of Vascular and Metabolic Research (S.H.S.), Yonsei University College of Medicine, Seoul, Korea.

This work was supported by a faculty research grant of Yonsei University College of Medicine for 2013 (6-2013-0051).

Please address correspondence to Sang Hyun Suh, MD, Department of Radiology, Gangnam Severance Hospital, Yonsei University, College of Medicine, 211 Eonju-ro, Gangnam-gu, Seoul 135-720, Korea; e-mail: SUHSH11@yuhs.ac

http://dx.doi.org/10.3174/ajnr.A4121 rysms. ${ }^{6,7}$ However, these imaging studies have some disadvantages in reality. ${ }^{8-13}$

In contrast, skull plain films have been conventional imaging tools because they are simple, inexpensive, less invasive, and applicable to every patient under any circumstances. However, the efficacy of skull plain films has been infrequently reported in the follow-up imaging of coiled aneurysms, ${ }^{14-16}$ in which the detailed methods used for analysis were obscure and their reliability questionable.

We aimed to evaluate the efficacy of skull plain films as follow-up imaging tools of coiled aneurysms by using quantitative assessment and to compare the subgroups by clinical parameters.

\section{MATERIALS AND METHODS \\ Patients}

Our institutional review board did not require its approval or informed consent for this retrospective study. Seventy patients (18 men, 52 women; age range, 33-75 years; mean age, 53 years) 
with 78 aneurysms (62 unruptured) from the institutional data base of 312 patients treated with detachable coils from 2005 to 2013 were enrolled in this study.

All treated aneurysms were the saccular type, neither fusiform nor dissection. The locations of aneurysms were the anterior communicating artery $(n=3)$, basilar tip $(n=14)$, cavernous ICA $(n=8)$, distal ICA $(n=46)$, posterior cerebellar artery $(n=$ $3)$, superior cerebellar artery $(n=3)$, and vertebral artery $(n=1)$. Aneurysms ranged from 2 to $13 \mathrm{~mm}$, with a mean diameter of 5.3 $\mathrm{mm}$. The mean angiographic follow-up period was 24 months (range, 12-71 months).

\section{Image Acquisition}

Seventy-eight paired skull plain films (156 images of skull anteroposterior $[\mathrm{AP}]$ and lateral views, respectively) were finally included. The initial skull plain films, including AP and lateral views, were obtained within 1 week after completion of coil embolization, and the next ones were obtained once every year during the follow-up period.

The skull plain films were obtained in digital radiography with a flat panel detector system (Digital Diagnost; Philips Healthcare, Best, Netherlands). The conventional method with the patient in a sitting position was used for skull plain films, ${ }^{17}$ in which the same focus-film distance was used with a constant $70 \mathrm{kV}$ and 400 $\mathrm{mA}$. The diameters and area of coil mass were measured by using a workstation for the PACS (Centricity PACS; GE Healthcare, Milwaukee, Wisconsin). The phantom study by using the radiopaque measuring ruler was performed to avoid possible measurement error from the PACS, and the measurement on the PACS was in good agreement with the ruler.

Cerebral angiographies were performed immediately after coil embolization and were repeated at 12 and 24 months after the procedures and were used to confirm the recurrence of the coiled aneurysm.

\section{Image Analysis}

The initial skull plain films were compared with the final ones obtained during the follow-up period. In cases with retreatment, the initial ones were compared with the last ones before retreatment.

Two independent radiologists (W.S.J., S.J.A.) estimated the largest diameter of the coil mass $\left(\mathrm{L}_{\mathrm{AP}}\right)$ and the diameter perpendicular to the $\mathrm{L}_{\mathrm{AP}}\left(\mathrm{P}_{\mathrm{AP}}\right)$ on the skull AP view. ${ }^{18}$ On the skull lateral view, the largest diameter $\left(\mathrm{L}_{\mathrm{Lat}}\right)$ and the diameter perpendicular to the $\mathrm{L}_{\text {Lat }}\left(\mathrm{P}_{\mathrm{Lat}}\right)$ were also measured in the same way. In measuring the area of the coil mass, a region of interest was drawn manually along the border of the coil mass on the skull plain films, and the areas on skull $\mathrm{AP}\left(\mathrm{A}_{\mathrm{AP}}\right)$ and lateral views $\left(\mathrm{A}_{\mathrm{Lat}}\right)$ were automatically calculated from the same image workstation (Figure). Quantitative change in each parameter was defined as the absolute difference of each parameter measured in the paired skull plain films.

The size of the aneurysm was defined as the maximal diameter of those measured in 3 planes of 3D DSA images before coiling. Packing attenuation, which was defined as the percentage of aneurysm volume filled with coil mass, was calculated by
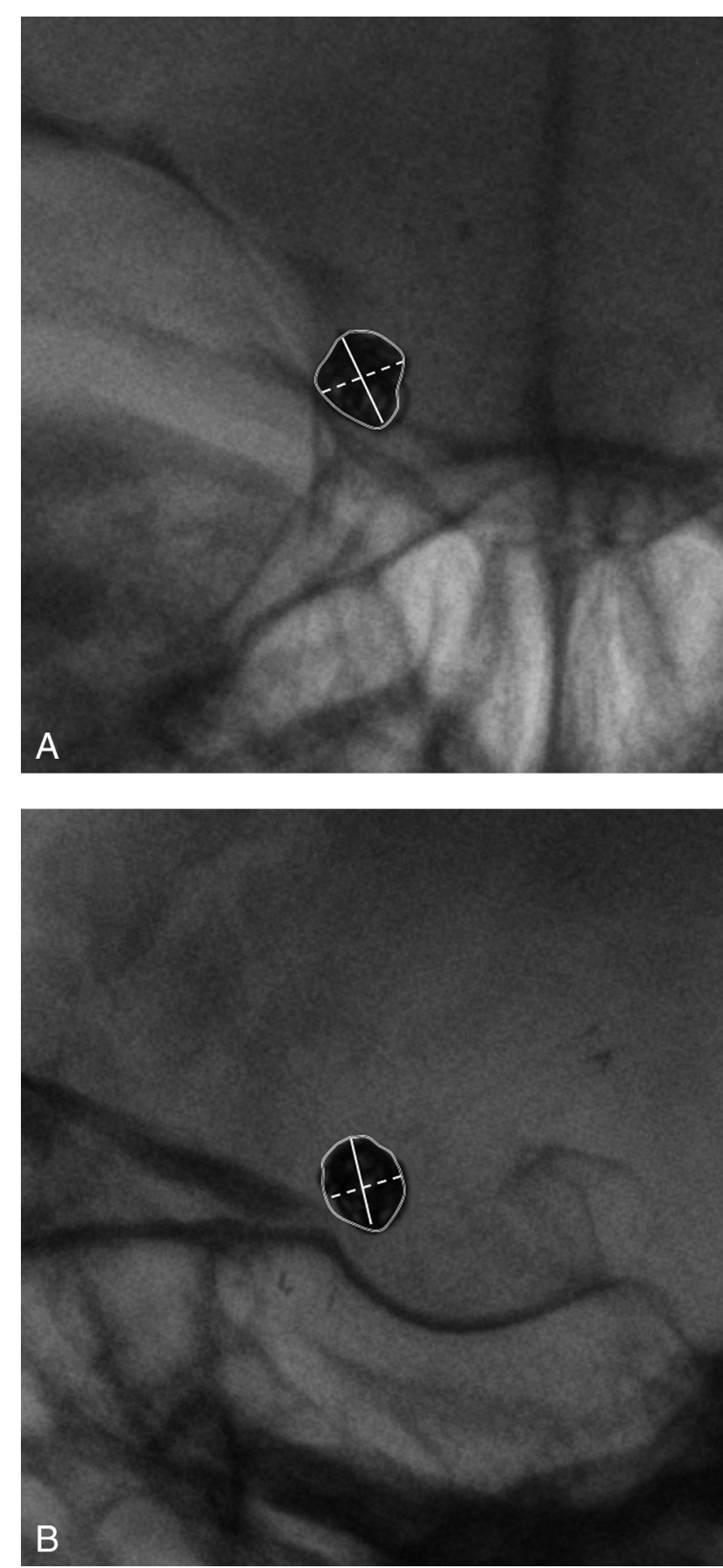

FIGURE. Quantitative measurement of a coiled aneurysm on the right distal ICA. The largest diameter, perpendicular diameter, and area of the coil mass are measured on skull AP $(A)$ and lateral $(B)$ views. The solid line indicates the largest diameter, and the dashed line is the perpendicular diameter. The area within the solid circle was automatically calculated.

using the software from the Web site AngioCalc (http://www. angiocalc.com).

Aneurysm recurrence was determined in consensus by 2 neuroradiologists (S.H.S., B.M.K.) by comparing the initial and last angiographies, and patients were divided into 2 groups: 1) Group A was defined as patients being stable or having minor morphologic changes of coiled aneurysms compared with the initial angiographies, and they did not need retreatment. On the follow-up 
Table 1: Comparison of patient demographics between subgroups ${ }^{a}$

\begin{tabular}{|c|c|c|c|}
\hline & Group A Aneurysm $(n=62)$ & Group B Aneurysm $(n=16)$ & $P$ Value \\
\hline Sex (female) & 49 & 6 & $<.01^{\mathrm{b}}$ \\
\hline Age (yr) & $53.82 \pm 8.83$ & $52.62 \pm 11.75$ & .65 \\
\hline Aneurysm size $(\mathrm{mm})$ & $5.10 \pm 2.35$ & $6.90 \pm 1.91$ & $<.01^{\mathrm{b}}$ \\
\hline Packing attenuation (\%) ${ }^{c}$ & $27.35 \pm 9.44(n=58)$ & $24.01 \pm 4.68(n=16)$ & .17 \\
\hline Follow-up (mo) & $24.90 \pm 19.95$ & $20.43 \pm 11.68$ & .39 \\
\hline Use of stent ${ }^{d}$ & $30(48.3 \%)$ & $3(18.7 \%)$ & .06 \\
\hline Ruptured aneurysm ${ }^{d}$ & $11(17.7 \%)$ & $5(31.2 \%)$ & .09 \\
\hline \multicolumn{4}{|l|}{ Initial angiographic result } \\
\hline Complete & 47 (75.8\%) & $11(68.7 \%)$ & .92 \\
\hline Near-complete & $15(24.2 \%)$ & $5(31.3 \%)$ & .92 \\
\hline Incomplete & 0 & 0 & \\
\hline
\end{tabular}

Table 2: Comparison of quantitative measurements on each skull plain film between subgroups $^{\mathrm{a}}$

\begin{tabular}{lccc}
\hline & $\begin{array}{c}\text { Group A } \\
\text { Aneurysm } \\
(\boldsymbol{n}=\mathbf{6 2})\end{array}$ & $\begin{array}{c}\text { Group B } \\
\text { Aneurysm } \\
(\boldsymbol{n}=\mathbf{1 6})\end{array}$ & $\begin{array}{c}\boldsymbol{P} \\
\text { Value }\end{array}$ \\
\hline AP image & & & \\
$\quad$ Differences in the largest diameter $(\mathrm{mm})$ & $0.54 \pm 0.52$ & $0.81 \pm 0.57$ & .07 \\
$\quad$ Differences in the perpendicular diameter $(\mathrm{mm})$ & $0.36 \pm 0.29$ & $0.47 \pm 0.59$ & .30 \\
$\quad$ Differences in area $\left(\mathrm{mm}^{2}\right)$ & $2.82 \pm 2.52$ & $5.12 \pm 9.26$ & .08 \\
Lateral image & & & \\
$\quad$ Differences in the largest diameter $(\mathrm{mm})$ & $0.53 \pm 0.43$ & $1.17 \pm 0.91$ & $<.01^{\mathrm{b}}$ \\
$\quad$ Differences in the perpendicular diameter $(\mathrm{mm})$ & $0.56 \pm 0.48$ & $1.20 \pm 1.05$ & $<.01^{\mathrm{b}}$ \\
$\quad$ Differences in area $\left(\mathrm{mm}^{2}\right)$ & $5.21 \pm 7.51$ & $10.55 \pm 10.93$ & $.02^{\mathrm{b}}$ \\
\hline
\end{tabular}

${ }^{a}$ Changes in each parameter mean the absolute difference of measurement from each skull view between the initial and follow-up periods.

${ }^{\text {b }}$ Statistically significant $(P<.05)$.

DSA, this group showed no interval change in the morphology of the coil mass. 2) Group B was defined as having major morphologic changes of the coil mass, such as significant coil compaction, contrast filling within the aneurysm sac, and coil loosening, compared with the initial treatment results. Most cases were retreated surgically or endovascularly.

\section{Statistical Analysis}

The interobserver agreement between 2 readers was evaluated by using the intraclass correlation coefficient, ${ }^{19}$ and an intraclass correlation coefficient $>0.75$ was considered good agreement. ${ }^{20}$

Continuous variables were presented as mean \pm SD. Quantitative changes in each parameter were compared by using an unpaired $t$ test between subgroups.

The diagnostic accuracy was measured by using the area under the receiver operating characteristic curves; and the area values of the largest diameter, the perpendicular diameter, and area of the coil mass were calculated in each skull plain film to predict aneurysm recurrence.

According to the aneurysm size, packing attenuation, use of stents, and the rupture status, the diagnostic accuracy of parameters was compared by using latent binomial alternative free-response receiver operating characteristic analysis. While the aneurysm size was subdivided by $5.3 \mathrm{~mm}$ of the reference size, the packing attenuation was classified by $24 \%$ of the aneurysm volume. $^{4}$

Statistical analysis was performed by using commercial soft- ware (MedCalc for Windows Version 10.1.2.0; MedCalc Software, Mariakerke, Belgium). A $P$ value $<.05$ was considered to be statistically significant.

\section{RESULTS}

The patient demographics are summarized in Table 1, and sex and aneurysm size were significantly different between subgroups $(P<.01)$.

In the skull lateral view, quantitative changes of 3 parameters $\left(\mathrm{L}_{\mathrm{Lat}}, \mathrm{P}_{\mathrm{Lat}}\right.$, and $\left.\mathrm{A}_{\text {Lat }}\right)$ were significantly different between subgroups $(P<.01, P<.01$, and $P=.02$, respectively, Table 2 ), but those of the skull AP view showed no significant difference.

In receiver operating characteristic analysis, the diagnostic accuracy of 3 parameters on the lateral view was higher than that on the AP view (Table 3). Among them, $\mathrm{P}_{\text {Lat }}$ had the highest accuracy of 0.74 with a sensitivity of $62.5 \%$, specificity of $85.4 \%$, positive predictive value of $45.4 \%$, and negative predictive value of $89.2 \%$. Only the accuracy of the $\mathrm{L}_{\mathrm{AP}}$ (area under the curve value of 0.66 , $P=.04$ ) was statistically significant in the AP view. However, there was no significant difference of diagnostic accuracy among $\mathrm{L}_{\mathrm{AP}}, \mathrm{L}_{\text {Lat }}, \mathrm{P}_{\text {Lat }}$, and $\mathrm{A}_{\text {Lat }}(P>.05)$.

While the diagnostic accuracy of $\mathrm{L}_{\mathrm{Lat}}$ and $\mathrm{P}_{\mathrm{Lat}}$ was dependent on high packing attenuation, $\mathrm{P}_{\text {Lat }}$ was a significant predictor in unruptured aneurysms (area under the curve value of $0.820, P<$ .05 , Table 4 ). However, the diagnostic accuracy of both parameters was independent of aneurysm size and the use of a stent.

The interobserver agreement in all parameters was excellent between the 2 readers (intraclass correlation coefficients for $\mathrm{L}_{\mathrm{AP}}$, diameter perpendicular to $\mathrm{L}_{\mathrm{AP}}, \mathrm{L}_{\text {Lat, }}, \mathrm{P}_{\text {Lat }}$, areas on skull $\mathrm{AP}$, and $\mathrm{A}_{\text {Lat }}$ were $0.98,0.99,0.98,0.99,0.99$, and 0.99, respectively).

\section{DISCUSSION}

In this study, all measurement parameters from skull plain lateral film achieved a feasible diagnostic performance. Quantitative changes of all parameters from the skull lateral view were significantly different between subgroups. In receiver operating characteristic analysis, 2 parameters from the lateral film may help to detect recanalization of the coiled aneurysms. The reason for this significant difference between the skull AP and lateral view is not clear, but we can extrapolate that the latter may be less affected by the following factors: 1) the direction of the aneurysm projection; 2) the aneurysm shape, such as spheric or ellipsoid; and 3) the patient position.

Few studies have shown the efficacy of skull plain films in the detection of aneurysm recurrence in patients with detachable coils. ${ }^{14-16}$ They focused mainly on the morphologic changes of coil mass and did not provide the quantitative information for 
Table 3: Analysis of each quantitative parameter on the skull plain films for prediction of aneurysm recurrence ${ }^{a}$

\begin{tabular}{|c|c|c|c|c|c|c|}
\hline & \multicolumn{3}{|c|}{ AP Image } & \multicolumn{3}{|c|}{ Lateral Image } \\
\hline & $\mathbf{L}$ & $\mathbf{P}$ & A & $\mathbf{L}$ & $\mathbf{P}$ & A \\
\hline AUC & $0.66(0.55 \sim 0.77)$ & $0.50(0.38 \sim 0.61)$ & $0.54(0.4 \sim 0.65)$ & $0.69(0.58 \sim 0.79)$ & $0.74(0.62 \sim 0.83)$ & $0.66(0.54 \sim 0.76)$ \\
\hline Sensitivity & $56.2(29.9 \sim 80.2)$ & $12.5(1.9 \sim 38.4)$ & $25.0(7.4 \sim 52.4)$ & $50.0(24.7 \sim 75.3)$ & $62.5(35.5 \sim 84.7)$ & $50.0(24.7 \sim 75.3)$ \\
\hline Specificity & $79.0(66.8 \sim 88.3)$ & 98.4 (91.3 99.7) & $90.3(80.1 \sim 96.3)$ & $90.3(80.1-\sim 96.3)$ & 85.5 (74.2 93.1) & $83.9(72.3 \sim 92.0)$ \\
\hline Cutoff value & 0.7 & 1.2 & 6.1 & 1.1 & 0.9 & 8.5 \\
\hline$P$ value & $.04^{\mathrm{b}}$ & .99 & .61 & $.01^{\mathrm{b}}$ & $<.01^{b}$ & $.04^{\mathrm{b}}$ \\
\hline
\end{tabular}

Note:- $L$ indicates largest diameter; P, perpendicular diameter; A, area; AUC, area under the curve.

${ }^{a}$ Data in parentheses are $95 \%$ confidence intervals.

${ }^{\mathrm{b}}$ Statistically significant $(P<.05)$.

Table 4: Comparison of AUC values between the largest and perpendicular diameter in skull lateral films ${ }^{a}$

\begin{tabular}{|c|c|c|c|}
\hline \multirow[b]{2}{*}{ Lateral Image } & \multicolumn{3}{|c|}{ AUC } \\
\hline & $\mathbf{L}$ & $\mathbf{P}$ & $P$ Value $^{\mathrm{b}}$ \\
\hline \multicolumn{4}{|l|}{ Size } \\
\hline$<5.3 \mathrm{~mm}(n=38)$ & $0.76(0.59 \sim 0.88)^{\mathrm{c}}$ & $0.82(0.66 \sim 0.92)^{c}$ & .55 \\
\hline$\geq 5.3 \mathrm{~mm}(n=40)$ & $0.77(0.62 \sim 0.89)^{c}$ & $0.83(0.68 \sim 0.93)^{c}$ & .59 \\
\hline \multicolumn{4}{|l|}{$P D^{d}$} \\
\hline$<24 \%(n=36)$ & $0.61(0.44 \sim 0.77)$ & $0.64(0.46 \sim 0.79)$ & .72 \\
\hline$\geq 24 \%(n=38)$ & $0.79(0.63 \sim 0.90)^{c}$ & $0.89(0.74 \sim 0.96)^{c}$ & .55 \\
\hline \multicolumn{4}{|l|}{ Stent } \\
\hline$(-)(n=45)$ & $0.69(0.54 \sim 0.82)^{c}$ & $0.69(0.53 \sim 0.82)^{c}$ & .96 \\
\hline$(+)(n=33)$ & $0.87\left(0.71 \sim 0.96^{\prime c}\right.$ & $0.88(0.72 \sim 0.96)^{c}$ & .80 \\
\hline \multicolumn{4}{|l|}{ Rupture status } \\
\hline$(-)(n=62)$ & $0.67(0.53 \sim 0.78)$ & $0.82(0.70 \sim 0.91)^{c}$ & .06 \\
\hline$(+)(n=16)$ & $0.76(0.49 \sim 0.93)$ & $0.59(0.32 \sim 0.83)$ & .21 \\
\hline
\end{tabular}

Note:-PD indicates packing attenuation; (-), coil embolization without stent (in "Stent"), unruptured aneurysm (in "Rupture status"); (+), stent-assisted coil embolization (in "Stent"), ruptured aneurysm (in "Rupture status"); L, largest diameter; $\mathrm{P}$, perpendicular diameter; AUC, area under the curve.

${ }^{a}$ Data in parentheses are $95 \%$ confidence intervals.

${ }^{b}$ AUC values between both diameters were compared.

'Statistically significant $(P<.05)$.

${ }^{\mathrm{d}}$ Seventy-four of 78 cases had the record of packing attenuation.

coiled aneurysms. Although Hwang et a ${ }^{16}$ first reported the usefulness of skull plain films in the prediction of aneurysm recurrence, they did not suggest the detailed morphologic criteria. Connor et a ${ }^{14}$ reported that morphologic changes of the coil mass showed an accuracy of $76 \%$ in the angiographic evaluation of aneurysm instability without quantitative information. In our study, $\mathrm{P}_{\text {Lat }}$ and $\mathrm{L}_{\text {Lat }}$ showed high accuracy (0.74 and 0.69) and specificity (85.5\% and $90.3 \%$ ) with cutoff values of 0.9 and 1.1 $\mathrm{mm}$, respectively.

Several studies showed that MRA has moderate-to-high diagnostic performance for detecting recurrence of coiled aneurysms, and it is becoming an alternative diagnostic option to invasive DSA techniques. ${ }^{21-23}$ Cottier et al ${ }^{15}$ proposed that the diagnostic performance of skull plain films was less accurate than TOFMRA. This study also showed that $\mathrm{P}_{\mathrm{Lat}}$ and $\mathrm{L}_{\mathrm{Lat}}$ have relatively low sensitivities (62.5\% and $50.0 \%$, respectively), which means that these parameters might not be appropriate as screening tools. There are still controversies with regard to size variation in the coil mass, ${ }^{14,15}$ in which the instability of aneurysm occlusion depends mainly on thrombus in the aneurysm and healing of the arterial wall rather than the morphologic changes of coil mass. ${ }^{24-26}$ Thus, the diameter variation of the coil mass should be carefully interpreted on serial lateral films of the cranium. However, in patients with claustrophobia, anxiety disorder, or economic hardship, skull plain films may be a complement to MRA. ${ }^{10,11}$ Unlike MRA, the additional advantage of skull plain films is that their diagnos- tic accuracy is not affected by the coil materials or device assistance, including stents. ${ }^{12,13}$

There were some limitations in this study. First, the study design was retrospective for a small number of cases, which might not be enough to draw a conclusion in proving the efficacy of skull plain films. Second, selection bias was ineluctable in this study because only the patients with initial and second follow-up skull plain films were enrolled. Future prospective study with larger populations across multiple centers is needed.

\section{CONCLUSIONS}

Quantitative measurement of the coil mass by using skull plain lateral film has the potential to predict aneurysm recurrence in the follow-up evaluation of intracranial aneurysms with coiling. Although a prospective study will be necessary for cost-effectiveness, skull plain films may be helpful in saving excessive medical expenses and reducing the radiation dose in patients without quantitative changes of the coiled mass by serial comparison of the skull plain films.

\section{REFERENCES}

1. Brilstra EH, Rinkel GJ, van der Graaf Y, et al. Treatment of intracranial aneurysms by embolization with coils: a systematic review. Stroke 1999;30:470-76

2. Molyneux A, Kerr R, Stratton I, et al. International Subarachnoid Aneurysm Trial (ISAT) of neurosurgical clipping versus endovascular coiling in 2143 patients with ruptured intracranial aneurysms: a randomised trial. Lancet 2002;360:1267-74

3. Sluzewski M, van Rooij WJ, Rinkel GJ, et al. Endovascular treatment of ruptured intracranial aneurysms with detachable coils: longterm clinical and serial angiographic results. Radiology 2003;227:720-24

4. Sluzewski M, van Rooij WJ, Slob MJ, et al. Relation between aneurysm volume, packing, and compaction in 145 cerebral aneurysms treated with coils. Radiology 2004;231:653-58

5. Raymond J, Guilbert F, Weill A, et al. Long-term angiographic recurrences after selective endovascular treatment of aneurysms with detachable coils. Stroke 2003;34:1398-403

6. Summers PE, Jarosz JM, Markus H. MR angiography in cerebrovascular disease. Clin Radiol 2001;56:437-56

7. Majoie CB, Sprengers ME, van Rooij WJ, et al. MR angiography at 3T 
versus digital subtraction angiography in the follow-up of intracranial aneurysms treated with detachable coils. AJNR Am J Neuroradiol 2005;26:1349-56

8. Hennemeyer CT, Wicklow K, Feinberg DA, et al. In vitro evaluation of platinum Guglielmi detachable coils at $3 \mathrm{~T}$ with a porcine model: safety issues and artifacts. Radiology 2001;219:732-37

9. Shellock FG. Biomedical implants and devices: assessment of magnetic field interactions with a 3.0-Tesla MR system. J Magn Reson Imaging 2002;16:721-32

10. Meléndez JC, McCrank E. Anxiety-related reactions associated with magnetic resonance imaging examinations. JAMA 1993; 270:745-47

11. Katznelson R, Djaiani GN, Minkovich L, et al. Prevalence of claustrophobia and magnetic resonance imaging after coronary artery bypass graft surgery. Neuropsychiatr Dis Treat 2008;4: 487-93

12. Lubicz B, Levivier M, Sadeghi N, et al. Immediate intracranial aneurysm occlusion after embolization with detachable coils: a comparison between MR angiography and intra-arterial digital subtraction angiography. J Neuroradiol 2007;34:190-97

13. Takayama $\mathrm{K}$, Taoka $\mathrm{T}$, Nakagawa $\mathrm{H}$, et al. Usefulness of contrastenhanced magnetic resonance angiography for follow-up of coil embolization with the Enterprise stent for cerebral aneurysms. J Comput Assist Tomogr 2011;35:568-72

14. Connor SE, West RJ, Yates DA. The ability of plain radiography to predict intracranial aneurysm occlusion instability during follow-up of endosaccular treatment with Gugliemi detachable coils. Neuroradiology 2001;43:680-86

15. Cottier JP, Bleuzen-Couthon A, Gallas S, et al. Follow-up of intracranial aneurysms treated with detachable coils: comparison of plain radiographs, 3D time-of-flight MRA and digital subtraction angiography. Neuroradiology 2003;45:818-24

16. Hwang GJ, Berenstein A, Niimi Y, et al. The accuracy of plain skull $\mathrm{x}$-ray examination as a predictor of recanalization following Gug- lielmi detachable coil embolisation in the treatment of cerebral aneurysms. Interv Neuroradiol 2000;6:195-202

17. Ballinger PW, Frank ED, Merrill V. Merrill's Atlas of Radiographic Positions and Radiologic Procedures. St. Louis: Elsevier Health Sciences; 2003

18. Parlea L, Fahrig R, Holdsworth DW, et al. An analysis of the geometry of saccular intracranial aneurysms. AJNR Am J Neuroradiol 1999;20:1079-89

19. Shrout PE, Fleiss JL. Intraclass correlations: uses in assessing rater reliability. Psychol Bull 1979;86:420-28

20. Kim SY, Lee SS, Byun JH, et al. Malignant hepatic tumors: shortterm reproducibility of apparent diffusion coefficients with breathhold and respiratory-triggered diffusion-weighted MR imaging. Radiology 2010;255:815-23

21. Farb RI, Nag S, Scott JN, et al. Surveillance of intracranial aneurysms treated with detachable coils: a comparison of MRA techniques. Neuroradiology 2005;47:507-15

22. Gauvrit JY, Leclerc X, Caron S, et al. Intracranial aneurysms treated with Guglielmi detachable coils: imaging follow-up with contrastenhanced MR angiography. Stroke 2006;37:1033-37

23. Agid R, Willinsky RA, Lee SK, et al. Characterization of aneurysm remnants after endovascular treatment: contrast-enhanced MR angiography versus catheter digital subtraction angiography. AJNR Am J Neuroradiol 2008;29:1570-74

24. Piotin M, Mandai S, Murphy KJ, et al. Dense packing of cerebral aneurysms: an in vitro study with detachable platinum coils. AJNR Am J Neuroradiol 2000;21:757-60

25. Reul J, Spetzger U, Weis J, et al. Endovascular occlusion of experimental aneurysms with detachable coils: influence of packing density and perioperative anticoagulation. Neurosurgery 1997;41:1160 65, discussion $1165-68$

26. Byrne JV, Hope JK, Hubbard N, et al. The nature of thrombosis induced by platinum and tungsten coils in saccular aneurysms. AJNR Am J Neuroradiol 1997;18:29-33 